\title{
Selective Degradation of Thymidine and Thymine Deoxynucleotides
}

\author{
BY K. BURTON AND W. T. RILEY* \\ Medical Research Council Cell Metabolism Unit, Department of Biochemistry, \\ University of Oxford
}

(Received 19 May 1965)

\begin{abstract}
1. Osmium tetroxide in dilute ammonia oxidizes various pyrimidine nucleosides at different rates. Thymidine is oxidized about 45 times as fast as deoxycytidine. The phosphate groups may be eliminated from oxidized thymine nucleotides by successive treatments with alkali and then with diphenylamine in aqueous formic acid. The reactions can be applied to the selective degradation of thymidine in oligodeoxynucleotides.
\end{abstract}

In this paper, we describe a procedure whereby thymidine may be chemically degraded with almost quantitative removal of the thymine and release of free deoxyribose. The same conditions release only a small proportion of the sugar groups from deoxycytidine. The method was devised because of its potential value in studying sequences of deoxynucleotides.

The procedure involves treatment with osmium tetroxide followed by successive treatments with dilute alkali and acid at mild temperatures. The reactions resemble those that have been reported to occur with brominated pyrimidines and their derivatives (Baudisch \& Davidson, 1925; Cohn, 1956; Roberts \& Friedkin, 1958). These involve conversion into a diol followed by opening of the pyrimidine ring to form an acid-labile ureidodeoxyriboside, e.g. as shown in Scheme 1. Osmium tetroxide is expected to convert thymidine into a 4,5-cis-diol, which should then undergo the same reactions in alkali and acid. These reactions should be the same for both ribo- and deoxyribo-nucleosides and for nucleotides. In this work we have principally studied the deoxyribose compounds because the treatment with alkali would prevent the application of the complete series of reactions to the study of nucleotide sequences in ribonucleic acids. The selectivity of the procedure that is described is due to the initial attack by the osmium tetroxide.

\section{MATERIALS}

Deoxynucleosides and deoxynucleotides. 'These were obtained from the California Corp. for Biochemical Research (Los Angeles, Calif., U.S.A.). Solutions of these and other nucleosides and nucleotides were standardized spectro-

* Present address : Sir William Dunn School of Pathology, University of Oxford. photometrically with the aid of values for their molar extinction coefficients as given by Burton (1959) and Burton \& Petersen (1960).

Deoxyribonucleic acid. DNA was isolated from herring testes (Emanuel \& Chaikoff, 1953).

Osmium tetroxide. The solid was obtained from Harrington Brothers Ltd. (London, E.C. 1) and an aqueous solution (approx. 5\%, w/v) was prepared, with precautions being taken to keep the toxic vapour away from the eyes (Pease, 1960). The solution was stored at $4^{\circ}$ and standardized spectrophotometrically. The molar extinction coefficient, $\epsilon_{260}=2500$, was determined on a solution that had, in turn, been standardized iodometrically (Klobbie, 1898; Ayres \& Wells, 1950). This coefficient is $13 \%$ higher than that found by Langseth \& Qviller (1934).

Oligonucleotides $\left(\mathrm{C}_{n} \mathrm{~T}\right) \mathrm{p}_{n+2}$. These oligonucleotides $\nmid$ were isolated from calf-thymus DNA as described in the preceding paper (Burton, 1966).

Amberlite $C G-50$. This resin was supplied by British Drug Houses Ltd. (Poole, Dorset) and the granule size was 100-200 mesh. Fines were removed by repeated decantation from water and the resin was washed as a column with successive $2 \mathrm{M}$ solutions of $\mathrm{KOH}, \mathrm{NaCl}, \mathrm{HCl}, \mathrm{KOH}, \mathrm{NaCl}$ and $\mathrm{HCl}$. The column was washed with water until the effluent was free from chloride, converted into the $\mathrm{NH}_{4}{ }^{+}$ form with $2 \mathrm{~N}-\mathrm{NH}_{3}$ and washed with water (adjusted to pH7 with aq. $\mathrm{NH}_{3}$ ) until the $\mathrm{pH}$ of the effluent reached $7 \cdot 5-8 \cdot 0$. This resin was stored in the refrigerator.

$\uparrow$ Abbreviations: Only deoxynucleotides are represented by abbreviated formulae and the prefix ' $d$ ' is omitted. $\mathrm{Pu}, \mathrm{C}$ and $\mathrm{T}$ represent a purine deoxynucleoside, deoxycytidine and thymidine respectively. The symbol $p$ to the right of a nucleoside symbol represents a phosphate group esterified to the $3^{\prime}$-hydroxyl of the nucleoside; when it is to the left it is a $5^{\prime}$-ester. Thus CpT represents deoxycytidyl$\left(3^{\prime}-5^{\prime}\right)$-thymidine. Sequences that are expected to consist of mixtures of isomeric nucleotides in unknown proportions are written with the nucleoside symbols in parentheses, e.g. (CT)p represents a mixture of $\mathrm{CpT}$ and $\mathrm{TpC}$. The numbering system used for the pyrimidine ring is that in which the ethylenic bond is numbered 4-5 and the glycoside $\mathrm{N}$ is numbered 3 (see Cohn \& Doherty, 1956). 


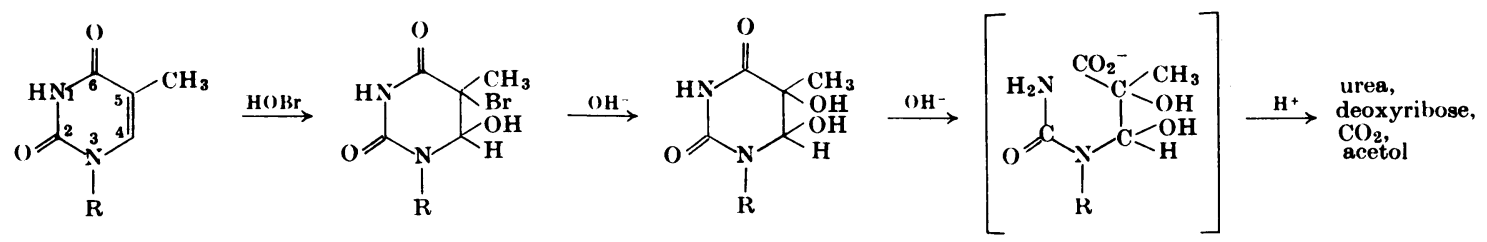

Scheme 1. R, Deoxyribosyl.

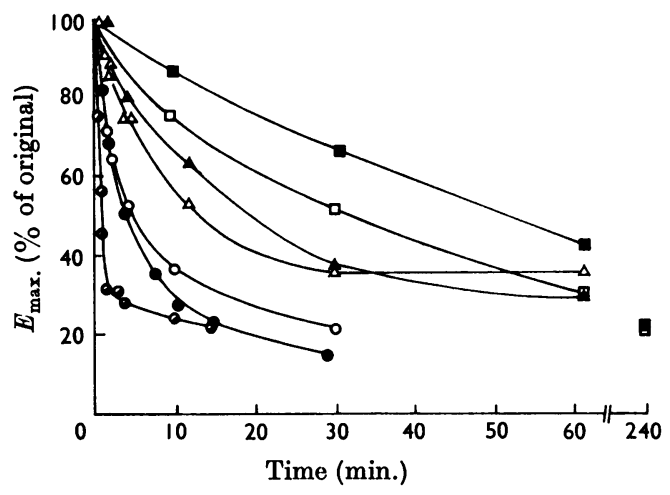

Fig. 1. Reaction of $\mathrm{OsO}_{4}$ with pyrimidine nucleosides. Each nucleoside $(2 \mathrm{~mm})$ was treated with $7 \mathrm{mM}^{-O_{s} O_{4}}$ in $0.4 \mathrm{~N}-\mathrm{NH}_{3}$ at $0^{\circ}$. Samples were removed at various times into $50 \mathrm{vol}$. of ice-cold ether, excess of $\mathrm{OsO}_{4}$ was removed by extraction into ether and the aqueous phase was diluted with $25 \mathrm{vol}$. of $0 \cdot 1 \mathrm{~N}-\mathrm{HCl}$. Zero-time samples were taken before the addition of the $\mathrm{OsO}_{4}$. The extinction coefficient of each sample was measured at the wavelength of maximum absorption for each nucleoside. $\square$, Cytidine $(280 \mathrm{~m} \mu)$; $\square$, deoxycytidine $(280 \mathrm{~m} \mu)$; O, 5-methyldeoxycytidine $(286 \mathrm{~m} \mu) ; \Delta$, uridine $(262 \mathrm{~m} \mu) ; \Delta$, deoxyuridine $(262 \mathrm{~m} \mu)$; $\bullet, 5$-bromodeoxyuridine $(279 \mathrm{~m} \mu) ; \oslash$, thymidine $(267 \mathrm{~m} \mu)$.

\section{METHODS •}

Removal of osmium tetroxide. Excess of $\mathrm{OsO}_{4}$ was removed from reaction mixtures and the oxidation stopped by extraction with diethyl ether, the partition coefficient into the ether being approx. 5. Small volumes (less than $0.5 \mathrm{ml}$.) were conveniently extracted by shaking in a glass-stoppered tube with 5-10 ml. of ice-cold ether, centrifuging and freezing the aqueous layer at the bottom of the tube by the use of either liquid air or solid $\mathrm{CO}_{2}$ and ethanol. The organic solvent was then poured off, the aqueous phase thawed and the extraction repeated.

Removal of potassium hydroxide. When the products were to be examined by chromatography or electrophoresis on paper, $\mathrm{K}^{+}$ions were removed by treatment with Amberlite CG-50 resin $\left(\mathrm{NH}_{4}{ }^{+}\right.$form). A $5 \mathrm{~cm} . \times 0.7 \mathrm{~cm}$. diam. column was sufficient for treating reaction mixtures of up to $10 \mathrm{ml}$. Nucleosides, nucleotides and their oxidized derivatives could be recovered quantitatively by washing the column with 4 bed-volumes of water that had been adjusted to pH 7 with aq. $\mathrm{NH}_{3}$ and the eluate contained less than
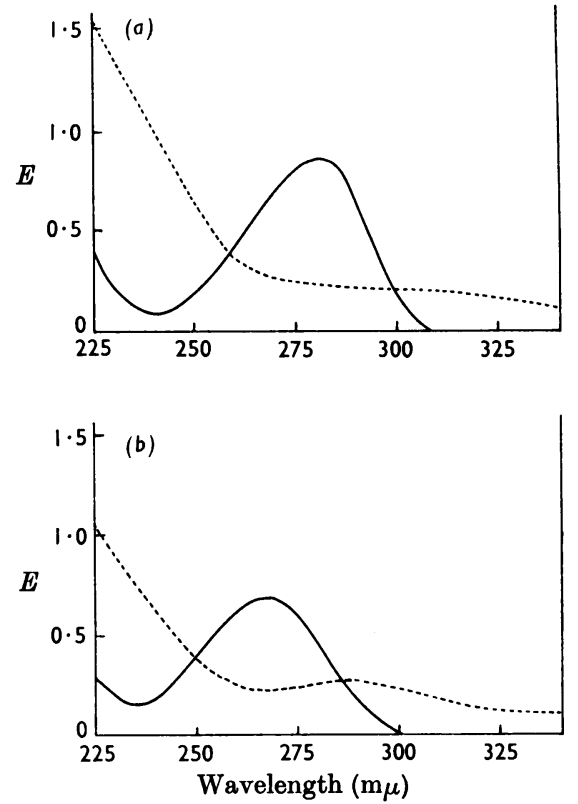

Fig. 2. Absorption spectra of nucleosides treated with $\mathrm{OsO}_{4}$. Each nucleoside (1mM) was treated with $\mathrm{OsO}_{4}$ in $\mathrm{NH}_{3}$ as described for Fig. 1, and the spectra were measured after dilution in $0 \cdot 1 \mathrm{~N}-\mathrm{HCl}$. (a) Deoxycytidine; $(b)$ thymidine. Solid lines are spectra before the addition of $\mathrm{OsO}_{4}$, broken lines after the reaction was complete, i.e. $3 \mathrm{hr}$. for $(a)$ and $15 \mathrm{~min}$. for $(b)$.

0.1mm-K $\mathrm{K}^{+}$ion. Excess of $\mathrm{NH}_{3}$ was removed by drying under vacuum in a rotary evaporator or by freeze-drying.

Phosphate estimations. $P_{i}$ was estimated by the method of Chen, Toribara \& Warner (1956) except in experiments where the reduced product of $\mathrm{OsO}_{4}$ interfered. This material did not interfere in the estimation of total phosphate because it was reoxidized and volatilized by the ashing in $\mathrm{HClO}_{4}-$ $\mathrm{H}_{2} \mathrm{SO}_{4}$ (Hanes \& Isherwood, 1949). Hence organic and inorganic phosphate could be determined separately by extraction of $P_{1}$ as the phosphomolybdate complex (Berenblum \& Chain, 1938, or Nielsen \& Lehninger, 1955) and by ashing samples from the two phases.

Colour reaction for deoxyribose. The periodate-thiobarbituric acid reaction (Waravdekar \& Saslaw, 1959) was used. In this method, free deoxyribose reacts, but combined forms such as nucleosides or nucleotides do not. 


\section{RESULTS}

Effects of osmium tetroxide on the absorption spectra of pyrimidine deoxynucleosides. Osmium tetroxide at $\mathrm{pH} 9$ or in dilute ammonia solution was found to lower the ultraviolet absorption of various pyrimidine deoxynucleosides at very different rates (Fig. 1) in the order: thymidine, 5-methyldeoxycytidine, deoxyuridine, deoxycytidine. Ribonucleosides react more slowly than the corresponding deoxynucleosides. The changes of spectra after prolonged reaction with osmium tetroxide are shown for thymidylate and deoxycytidylate in Fig. 2. After shorter reaction times, the spectra between 260 and $300 \mathrm{~m} \mu$ gave no indication of intermediate products that absorbed in this region. One mole of osmium tetroxide is sufficient to depress the absorption of 1 mole of thymidine to its final value at $267 \mathrm{~m} \mu$ (Fig. 3).

The rate of reaction is only slightly affected by phosphate substituents on the sugar, the relative rates being approximately: thymidine, 1.0 ; thymidine $5^{\prime}$-phosphate, $0 \cdot 85$; thymidine $3^{\prime}, 5^{\prime}$-diphosphate, 0.95 (Fig. 4). The linearity of these plots indicates that the reaction is first-order with respect to the thymidine compound. The rate of reaction increases in proportion to the concentration of osmium tetroxide, but the increase with the concentration of ammonia is not strictly proportional (Table 1). Essentially similar results were obtained for deoxycytidine $5^{\prime}$-phosphate (Table 1), and no conditions were found to alter significantly the relative rates of reaction of thymidylate and deoxycytidylate.

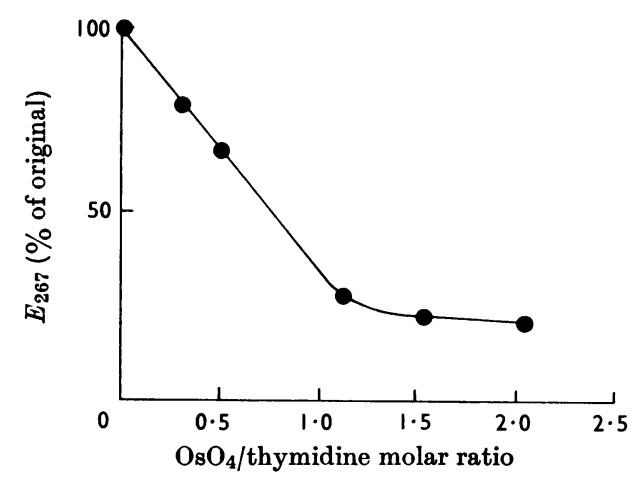

Fig. 3. Stoicheiometry of the reaction between $\mathrm{OsO}_{4}$ and thymidine. Thymidine $(2 \mathrm{mM})$ in $0.1 \mathrm{~N}-\mathrm{NH}_{3}$ was mixed with $17 \mathrm{~mm}-\mathrm{OsO}_{4}$ in various proportions and the mixtures were left at room temperature in glass-stoppered tubes. After 22 and after $45 \mathrm{hr}$., the extinction coefficient of the nucleoside $\left(E_{267}\right)$ was measured as described in Fig. 2. There were no significant differences between the values for the two times, showing that the reaction was complete.
Absence of appreciable action of osmium tetroxide on purine deoxynucleotides. Deoxyadenosine $5^{\prime}$ phosphate and deoxyguanosine $5^{\prime}$-phosphate ( $2 \mathrm{mM}$ ) were each treated with $7 \mathrm{~mm}$-osmium tetroxide in $0.1 \mathrm{~N}$-ammonia at $0^{\circ}$ for 1 week and about $80 \%$ of each purine nucleotide was recovered unchanged after paper chromatography in propan-2-ol-water $(7: 3, v / v)$.

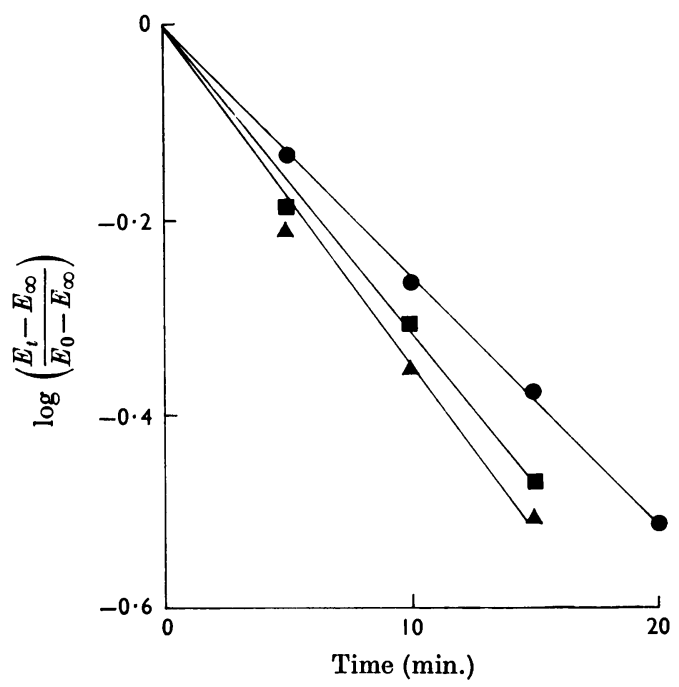

Fig. 4. Rates of reaction of $\mathrm{OsO}_{4}$ with thymidine and thymidine phosphates. Each compound (1 mM) was treated with $3.5 \mathrm{mM}^{-\mathrm{OsO}_{4}}$ in $0.1 \mathrm{~N}-\mathrm{NH}_{3}$ at $0^{\circ}$. At various times, samples were removed, excess of $\mathrm{OsO}_{4}$ was removed and the extinction coefficient $(E)$ was measured at $267 \mathrm{~m} \mu$. The ordinate indicates $\log \left[\left(E_{t}-E_{\infty}\right) /\left(E_{0}-E_{\infty}\right)\right]$ where $E_{0}$ is the value of $E$ at zero time, $E_{t}$ is that at time $t$ and $E_{\infty}$ is that when the reaction was complete. $\Delta$, Thymidine; -, thymidine $5^{\prime}$-phosphate;, thymidine $3^{\prime}, 5^{\prime}$-diphosphate.

Table 1. Rates of oxidation of nucleotides by ammoniacal osmium tetroxide at different concentrations of reactants

Reaction rates at room temperature were measured spectrophotometrically as indicated in Fig. 1. For each nucleotide the rates are expressed relative to the first value shown.

\begin{tabular}{|c|c|c|c|c|}
\hline & $\begin{array}{l}\text { Conen. } \\
\text { of } \mathrm{NH}_{3} \\
(\mathrm{~N})\end{array}$ & $\begin{array}{c}\text { Concn. } \\
\text { of } \mathrm{OsO}_{4} \\
(\mathrm{mM})\end{array}$ & $\begin{array}{c}\text { Concn. of } \\
\text { nucleotide } \\
(\mathrm{mM})\end{array}$ & $\begin{array}{l}\text { Relative } \\
\text { reaction } \\
\text { rate }\end{array}$ \\
\hline hymidylate & $\begin{array}{l}0 \cdot 1 \\
0 \cdot 1 \\
0 \cdot 4\end{array}$ & $\begin{array}{l}0.58 \\
0.29 \\
0.59\end{array}$ & $\begin{array}{l}0.06 \\
0.06 \\
0.06\end{array}$ & $\begin{array}{c}(1 \cdot 0) \\
0 \cdot 48 \\
6 \cdot 3\end{array}$ \\
\hline $\begin{array}{l}\text { eoxycyti- } \\
\text { dylate }\end{array}$ & $\begin{array}{l}0 \cdot 1 \\
0 \cdot 4 \\
0 \cdot 4 \\
0 \cdot 4\end{array}$ & $\begin{array}{r}11 \cdot 4 \\
5 \cdot 7 \\
11 \cdot 4 \\
22 \cdot 8\end{array}$ & $\begin{array}{l}0 \cdot 64 \\
0 \cdot 64 \\
0 \cdot 64 \\
0 \cdot 32\end{array}$ & $\begin{array}{c}(1 \cdot 0) \\
2 \cdot 1 \\
4 \cdot 2 \\
4 \cdot 2\end{array}$ \\
\hline
\end{tabular}


Action of alkali on oxidized pyrimidine nucleosides and nucleotides. After oxidation of thymidine or thymidylate with osmium tetroxide, incubation with potassium hydroxide facilitates the reaction of the reactive C-1 group of the deoxyribose. Unfortunately, analysis of the products is complicated by the accompanying reduced forms of osmium tetroxide, which interfere in the colorimetric estimation of deoxyribose by the diphenylamine reaction (Burton, 1956). However, these materials are not present in sufficient quantities to interfere in the periodate-thiobarbituric acid method for deoxyribose (Waravdekar \& Saslaw, 1959), and by suitable methods it is also possible to follow the release of $P_{1}$ from oxidized nucleotides when they are degraded by diphenylamine and formic acid (Burton, 1956; Burton \& Petersen, 1960). Some results obtained in these types of experiment are shown in Table 2 . Thymidylate releases its $P_{1}$ after successive treatments with osmium tetroxide, alkali and diphenylamine in aqueous formic acid. However, when thymidine is oxidized and treated with alkali, it does not yield deoxyribose quantitatively in the periodate-thiobarbituric acid reaction unless the solution is treated with dilute acid before the reaction with periodate (Table 2). This behaviour indicates that, after the treatment with

Table 2. Action of alkali on thymidine and thymidine 5'-phosphate that had been oxidized by osmium tetroxide

The compounds were treated with $7 \mathrm{mM}^{-\mathrm{OsO}_{4}}$ in $0.1 \mathrm{~N}$ $\mathrm{NH}_{3}$ for $50 \mathrm{~min}$. Excess of reagent was removed by ether extraction, and $2 \mathrm{~N}-\mathrm{KOH}$ was added to give a final concentration of $0 \cdot 1 \mathrm{~N}$. Duplicate samples were removed from the thymidine reaction mixture into $0.3 \mathrm{vol}$. of $2 \mathrm{~N}-\mathrm{HCl}$. One of the samples $(A)$ was diluted with $5 \mathrm{ml}$. of water and stored at $4^{\circ}$; the other $(B)$ was heated at $70^{\circ}$ for $15 \mathrm{~min}$. before dilution with water. Deoxyribose was then determined in both samples by the periodate-thiobarbituric acid reaction (Waravdekar \& Saslaw, 1959). Samples from the thymidine 5 -phosphate reaction mixture were added to 2 vol. of $3 \%$ $(w / v)$ diphenylamine in $98 \%(v / v)$ formic acid. Inorganic and organic phosphate were determined after incubation at $30^{\circ}$ for $17 \mathrm{hr}$.

\begin{tabular}{|c|c|c|c|}
\hline \multirow[b]{2}{*}{$\begin{array}{l}\text { Duration } \\
\text { of KOH } \\
\text { treatment } \\
\text { (min.) }\end{array}$} & \multicolumn{2}{|c|}{$\begin{array}{c}\text { Deoxyribose released } \\
\text { from thymidine } \\
\text { (\% of theoretical) }\end{array}$} & \multirow{2}{*}{$\begin{array}{c}\mathbf{P}_{\mathbf{i}} \\
\text { released } \\
\text { from } \\
\text { thymidine } \\
5^{\prime} \text {-phosphate } \\
\text { (\% of total } \\
\text { phosphate) }\end{array}$} \\
\hline & $\begin{array}{l}\text { No acid } \\
\text { treatment } \\
\quad(A)\end{array}$ & $\begin{array}{l}\text { After acid } \\
\text { hydrolysis } \\
\qquad(B)\end{array}$ & \\
\hline 0 & 5 & 20 & 15 \\
\hline 30 & 25 & 72 & 68 \\
\hline 60 & 26 & 80 & 91 \\
\hline 90 & 30 & 94 & 93 \\
\hline 120 & 31 & 96 & 93 \\
\hline
\end{tabular}

alkali, an acid-labile group is still attached to C-1 of the deoxyribose, and suggests that the expected ureidoglycoside is indeed formed (cf. Cohn \& Doherty, 1956). Further confirmation of this mechanism was given by the fact that the solution gave a colour reaction for urea (Coulombe \& Favreau, 1963) and a fluorimetric reaction for acetol (Roberts \& Friedkin, 1958).

The time-course of phosphate release in the diphenylamine and formic acid mixture (Fig. 5) is similar to that from deoxyadenylate or deoxyguanylate and slower than that from apurinic acid (Burton \& Petersen, 1960).

On prolonged treatment at $0^{\circ}$, deoxycytidylate may be completely oxidized by osmium tetroxide, but subsequent treatment with $0 \cdot 1 \mathrm{~N}$-potassium hydroxide for 2 or $4 \mathrm{hr}$. at $37^{\circ}$ followed by reaction with diphenylamine and formic acid for $15 \mathrm{hr}$. at $30^{\circ}$ only released $25 \%$ of the phosphate as $P_{i}$. The amounts of $P_{1}$ released from thymidylate and deoxycytidylate are compared in Fig. 6 after reaction with osmium tetroxide for various periods : the eventual release of $P_{i}$ parallels the initial effect of the osmium tetroxide on the u.v. absorption of the nucleotides.

Degradation of pyrimidine oligonucleotides and of $D N A$. As a result of the findings of the above experiments with the monopyrimidine nucleotides, several oligonucleotides of the series $\left(C_{n} T\right) p_{n+2}$ were treated with osmium tetroxide and the products were examined by paper electrophoresis at $\mathrm{pH} 2 \cdot 7$, in some cases followed by chromatography at right angles to the direction of electrophoresis. These separations do not resolve the sequential isomers of

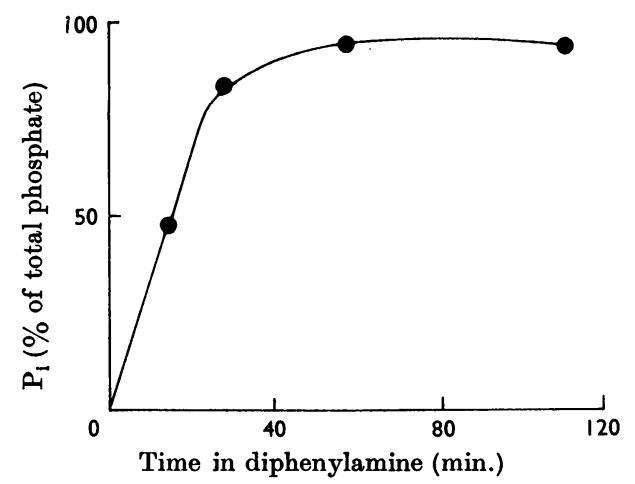

Fig. 5. Time-course of the diphenylamine-induced release of phosphate from thymidylate after treatment with $\mathrm{OsO}_{4}$ and alkali. Thymidylate was treated with $7 \mathrm{mM}^{-\mathrm{OsO}_{4}}$ in $0 \cdot 1 \mathrm{~N}-\mathrm{NH}_{3}$ at $0^{\circ}$ for $45 \mathrm{~min}$. and then with $0.1 \mathrm{~N}-\mathrm{KOH}$ at $37^{\circ}$ for $90 \mathrm{~min}$. The solution was mixed with 2 vol. of $3 \%$ $(w / v)$ diphenylamine in $98 \%(v / v)$ formic acid at $30^{\circ}$. Organic phosphate and total phosphate were measured at different times. 
Table 3. Release of cytosine nucleotides from oligonucleotides of formula $\left(\mathrm{C}_{n} \mathrm{~T}\right) \mathrm{p}_{n+3}$

The oligonucleotides (2mM) were treated with $7 \mathrm{mM}-\mathrm{OsO}_{4}$ in $0.4 \mathrm{~N}-\mathrm{NH}_{3}$ at $0^{\circ}$ for the times shown, excess of $\mathrm{OsO}_{4}$ was removed by extraction and the solution was incubated at $37^{\circ}$ for $2 \mathrm{hr}$. with $0.05 \mathrm{vol}$. of $2 \cdot 1 \mathrm{~N}-\mathrm{KOH}$. The solution was desalted by treatment with Amberlite CG-50 ( $\mathrm{NH}_{4}+$ form) and freeze-drying and then incubated with $2 \%$ (w/v) diphenylamine in $66 \%(\mathrm{v} / \mathrm{v})$ formic acid at $37^{\circ}$ for $1 \mathrm{hr}$., except in the one instance indicated. The products were separated and compared with authentic $\mathrm{C}_{n} \mathrm{p}_{n+1}$ compounds by paper electrophoresis at pH 2.7 (Petersen, 1963 ) followed in some cases by chromatography at right angles in propan-2-ol-water (3:2 or 7:3, v/v). Residual oligonucleotide includes material that appears to have been modified without breaking the internucleotide bonds.

\begin{tabular}{|c|c|c|c|c|c|c|c|}
\hline \multirow[b]{3}{*}{ Oligonucleotide } & \multirow{3}{*}{$\begin{array}{l}\text { Time } \\
\text { with } \\
\mathrm{OsO}_{4} \\
\text { (min.) }\end{array}$} & \multicolumn{2}{|c|}{ Residual oligonucleotide } & \multirow{2}{*}{\multicolumn{4}{|c|}{$\begin{array}{l}\text { Distribution of cytosine } \\
\text { among products detected }(\%)\end{array}$}} \\
\hline & & \multirow{2}{*}{$\begin{array}{l}\text { Amount (\% } \\
\text { of u.v. absorption } \\
\text { at } 267 \mathrm{~m} \mu \text { eluted) }\end{array}$} & \multirow{2}{*}{$\begin{array}{l}E_{280} / E_{260} \\
\quad \text { ratio }\end{array}$} & & & & \\
\hline & & & & $\mathrm{Cp}_{2}$ & $\mathrm{C}_{2} \mathrm{p}_{3}$ & $\mathrm{C}_{3} \mathrm{p}_{4}$ & $\mathrm{C}_{4} \mathrm{p}_{5}$ \\
\hline \multirow[t]{2}{*}{$(\mathrm{CT}) \mathrm{p}_{3}$} & 5 & 29 & $1 \cdot 4$ & 100 & - & - & - \\
\hline & 11 & 11.5 & $1 \cdot 9$ & 100 & - & - & - \\
\hline \multirow[t]{5}{*}{$\left(\mathrm{C}_{2} \mathrm{~T}\right) \mathrm{p}_{4}$} & 7 & 11 & $1 \cdot 9$ & $49 \cdot 5$ & $50 \cdot 5$ & 一 & - \\
\hline & 10 & 6-9 & & 50 & 50 & - & - \\
\hline & 11 & 20 & $2 \cdot 0$ & $49 \cdot 5$ & $50 \cdot 5$ & - & - \\
\hline & 15 & 10 & & 54 & 46 & - & - \\
\hline & 40 & 6 & & 57 & 43 & - & - \\
\hline \multirow[t]{2}{*}{$\left(\mathrm{C}_{3} \mathrm{~T}\right) \mathrm{p}_{5}$} & 6 & 18 & $2 \cdot 0$ & 40 & 34 & 26 & - \\
\hline & $6^{*}$ & 8.5 & $2 \cdot 0$ & 39 & $\mathbf{3 4} \cdot 5$ & $26 \cdot 5$ & - \\
\hline$\left(\mathrm{C}_{4} \mathrm{~T}\right) \mathrm{p}_{6}$ & 7 & 15 & 1.95 & 33.5 & $24 \cdot 5$ & 22 & 20 \\
\hline
\end{tabular}

* Treated with diphenylamine and formic acid for $17 \mathrm{hr}$. at $30^{\circ}$.

isomeric $\left(\mathrm{C}_{n} \mathrm{~T}\right) \mathrm{p}_{n+2}$ mixtures. During treatment with osmium tetroxide in $0.4 \mathrm{~N}$-ammonia, the $E_{280} / E_{260}$ ratio (measured at $\mathrm{pH}$ 1-2) increased as the thymine residue reacted. In each case, only one ultravioletabsorbing spot ( $E_{280} / E_{260}$ ratio about 2 at $\left.\mathrm{pH} 1-2\right)$ was detected and it had virtually the same electrophoretic mobility as the original isomeric nucleotides, indicating that the internucleotide linkages were not affected. The treatment with potassium hydroxide slightly decreased the mobility but again only one component was seen. After treatment with diphenylamine, the expected $\mathrm{C}_{n} \mathrm{p}_{n+1}$ products were found (Table 3), and, in addition, there was some material with mobilities similar to those of the original oligonucleotides but with a higher $E_{280} / E_{260}$ ratio. Apparently the thymine had been oxidized but the internucleotide bonds had not been broken. The incomplete cleavage was principally due to the short time of reaction with diphenylamine [see the second experiment with $\left(\mathrm{C}_{3} \mathrm{~T}\right) \mathrm{p}_{5}$ in Table 3] and so, in all subsequent experiments, the diphenylamine reaction was carried out at $30^{\circ}$ for at least $15 \mathrm{hr}$.

Table 3 also shows that the reaction with osmium tetroxide was not complete at $5 \mathrm{~min}$. but was essentially complete after about $7 \mathrm{~min}$. in $0.4 \mathrm{~N}$ ammonia at $0^{\circ}$. As expected, pCp was the principal u.v.-absorbing material present after degradation of the mixed isomers pCpTp and pTpCp. The expected products were also given by each of the higher homologues, e.g. $\left(\mathrm{C}_{2} \mathrm{~T}\right) \mathrm{p}_{4}$ gave $\mathrm{pCp}$ and pCpCp. It is noteworthy that $\left(\mathrm{C}_{4} \mathrm{~T}\right) \mathrm{p}_{6}$ gave a good

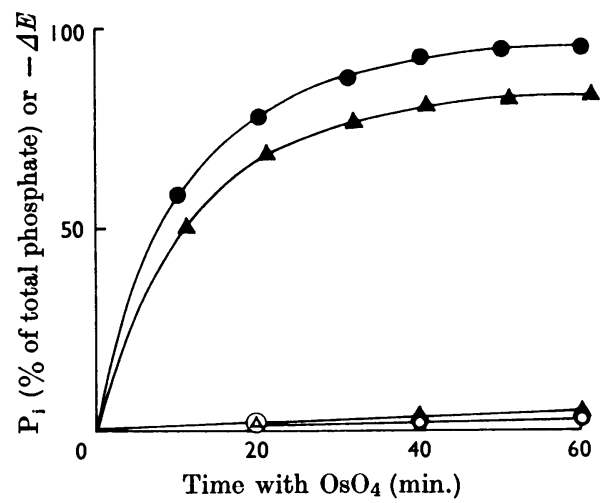

Fig. 6. Effects of different times of incubation with $\mathrm{OsO}_{4}$. Thymidylate or deoxycytidylate $(2 \mathrm{~mm})$ was treated with $7 \mathrm{mM}^{-\mathrm{OsO}_{4}}$ in $0.1 \mathrm{~N}: \mathrm{NH}_{3}$ at $0^{\circ}$. After the removal of excess of $\mathrm{OsO}_{4}$, samples were diluted in $0.1 \mathrm{~N}-\mathrm{HCl}$ and the percentage fall of extinction coefficient $(-\Delta E)$ was determined at $267 \mathrm{~m} \mu$ for thymidylate $(\Delta)$ and at $280 \mathrm{~m} \mu$ for deoxycytidylate $(\Delta)$. Other samples were incubated for $2 \mathrm{hr}$. with $0.1 \mathrm{~N}-\mathrm{KOH}$ at $37^{\circ}$ and then in $2 \%(\mathrm{w} / \mathrm{v})$ diphenylamine in $66 \%(v / v)$ formic acid for $12 \mathrm{hr}$. at $30^{\circ}$. $P_{1}$ (as $\%$ of total phosphate): $\bullet$, thymidylate; $\bigcirc$, deoxycytidylate.

yield of $\mathrm{C}_{4} \mathrm{p}_{5}$. Though these results are those to be expected from a completely specific removal of the thymidine residues from the original oligonucleotides, closer examination shows that there has also 
been some degradation of cytosine nucleotides, as is to be expected from the kinetics of the reaction of osmium tetroxide with nucleosides and mononucleotides. For example, more pCp than pCpCp was released from $\left(\mathrm{C}_{3} \mathrm{~T}\right) \mathrm{p}_{5}$, whereas these products should appear in equimolar amounts because they should come only from the isomers pCpCpTpCp and pCpTpCpCp. The actual ratio was about 1.2:2. Similarly, $\left(\mathrm{C}_{4} \mathrm{~T}\right) \mathrm{p}_{6}$ gave 1.5 times as much pCp as $\mathrm{C}_{3} \mathrm{p}_{4}$ when equimolar amounts were again expected. After degradation of $\left(\mathrm{C}_{2} \mathrm{~T}\right) \mathrm{p}_{4}$, the ratio of $\mathrm{pCp}$ to pCpCp increased with the time of reaction with osmium tetroxide. Likewise, the amount of $\mathbf{P}_{\mathbf{1}}$ increases with the reaction time and eventually goes above the theoretical limit of $33 \%$ with (CT) $p_{3}$ (Fig. 7). These effects could be explained by oxidation of about $1 \%$ of the deoxycytidine residues/min. (in $0.4 \mathrm{~N}$-ammonia). Fig. 7 also shows that heated DNA reacts readily with osmium tetroxide, whereas native DNA is slowly and incompletely attacked.

In other experiments (Tables 4 and 5) diphenylamine digests of herring DNA were treated with osmium tetroxide, and the cytosine nucleotides that

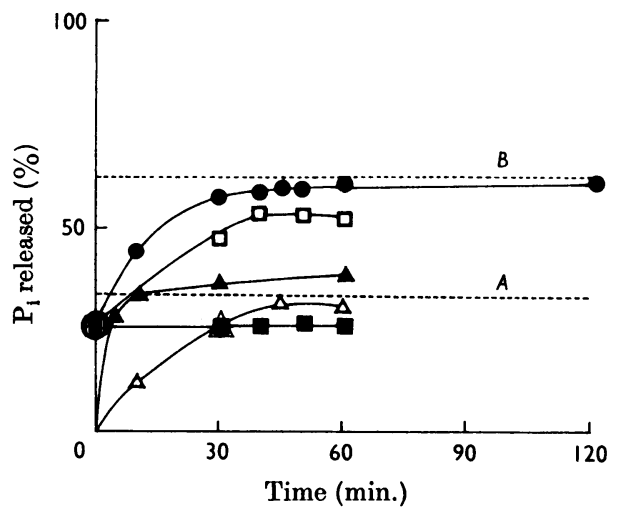

Fig. 7. Release of $P_{1}$ from oligonucleotides and DNA treated with $\mathrm{OsO}_{4}$. Concentrations were adjusted so that $1 \mathrm{ml}$. of nucleotide solution contained $2 \mu$ moles of thymine. Solutions were then treated at $0^{\circ}$ with $7 \mathrm{mM}^{-\mathrm{OsO}_{4}}$ in $0.1 \mathrm{~N}-$ or $0.4 \mathrm{~N}-\mathrm{NH}_{3}$ as indicated. At different times, samples were shaken with ether to remove excess of $\mathrm{OsO}_{4}$, incubated with $0.05 \mathrm{vol}$. of $2.1 \mathrm{~N}-\mathrm{KOH}$ for $2 \mathrm{hr}$. at $37^{\circ}$ and then mixed with 2 vol. of $3 \%(w / v)$ diphenylamine in $98 \%(v / v)$ formic acid and incubated at $30^{\circ}$ for $15-17 \mathrm{hr}$. $\bullet$, Diphenylamine digest of herring DNA; $\square$, heat-denatured herring DNA; $\square$, native herring DNA; $\Delta,(\mathrm{CT}) \mathrm{p}_{3} ; \boldsymbol{\Delta},(\mathrm{CT}) \mathrm{p}_{3}$ treated with $\mathrm{OsO}_{4}$ in $0.4 \mathrm{~N}-\mathrm{NH}_{3}$. Except for the last series of values $0 \cdot 1 \mathrm{~N}-\mathrm{NH}_{3}$ was used. The broken horizontal lines $A$ and $B$ show theoretical maximum yields from (CT) $p_{3}$-diphenylamine and DNA-diphenylamine digests respectively. These yields were calculated assuming no degradation of cytosine and, for $B$, assuming a random arrangement of nucleotides in the DNA chains. were eventually liberated were separated on paper by two-dimensional procedures. For the experiments in Table 4 the digest was treated with prostatic phosphomonoesterase as described by Burton \& Petersen (1960) before reaction with osmium tetroxide. In this case, the amounts of $\mathrm{CpC}$ and $\mathrm{CpCpC}$ nucleotides should not have been affected by the osmium treatment and, within the analytical errors of the experiment, this appears to be so. Appreciable amounts of several oligonucleotides containing one thymine nucleotide residue were also observed among the products in these experiments and indicate that the conditions of oxidation were not satisfactory.

Recommended conditions for selective degradation. The experiments in Fig. 7 and Tables 4 and 5 show that satisfactory results may be obtained by the following procedure. The oligonucleotide to be degraded is dissolved in $0.4 \mathrm{~N}$-ammonia so that $1 \mathrm{ml}$. of the solution contains about $2 \mu$ moles of thymine. The solution is cooled to $0^{\circ}$ and osmium tetroxide $(0.05-0.2 \mathrm{M})$ is added to give a final concentration of $7 \mathrm{~mm}$. We consider that it is important to check each sample of osmium tetroxide by determining the rate of reaction with thymidylate. The $E_{267}$ value after ether extraction should fall to $50 \%$ of the initial value in $10-11 \mathrm{~min}$. in $0.1 \mathrm{~N}$-ammonia. One sample that reacted at about half this rate

Table 4. Products obtained by treating a diphenylamine digest of DNA with prostatic phosphatase followed by successive treatments with osmium tetroxide, alkali and acidic diphenylamine

A diphenylamine digest of herring DNA was treated with prostatio phosphatase. After removal of protein the product was treated with $\mathrm{OsO}_{4}$ for $45 \mathrm{~min}$. in $0.1 \mathrm{~N}-\mathrm{NH}_{3}$ at $0^{\circ}$. The treatments with alkali and acidic diphenylamine are described in the legend to Fig. 7. The mixture was then subjected to two-dimensional separation on paper, according to either Burton \& Petersen (1960) or Petersen (1963). Individual values are shown. As the amounts of $\mathrm{C}_{n} \mathrm{P}_{n-1}$ compounds should show no change, some data from Burton (1960) are included for comparison.

\begin{tabular}{|c|c|c|c|}
\hline Product & $\begin{array}{c}\begin{array}{c}\text { Amount } \\
\text { (moles of }\end{array} \\
\text { cytosine/100 moles } \\
\text { of DNA } \\
\text { phosphate) }\end{array}$ & $\begin{array}{l}\text { Amount } \\
\text { expected for } \\
\text { randomly } \\
\text { arranged } \\
\text { polynucleotide }\end{array}$ & $\begin{array}{r}\text { Burton } \\
(1960)\end{array}$ \\
\hline $\mathrm{C}$ & $5 \cdot 3,5 \cdot 7,6 \cdot 2$ & $5 \cdot 35$ & $5 \cdot 9$ \\
\hline $\mathrm{Cp}$ & $3 \cdot 7,4 \cdot 8^{*}$ & $6 \cdot 09$ & \\
\hline $\mathrm{Cp}_{2}$ & $1 \cdot 0,1 \cdot 1,1 \cdot 1$ & $1 \cdot 76$ & \\
\hline $\mathrm{C}_{2} \mathrm{p}$ & $1 \cdot 4,1 \cdot 5,1 \cdot 8$ & $2 \cdot 20$ & $1 \cdot 8$ \\
\hline $\mathrm{C}_{2} \mathrm{p}_{2}$ & $1 \cdot 1,1 \cdot 5,1 \cdot 6$ & $2 \cdot 55$ & \\
\hline $\mathrm{C}_{3} \mathrm{p}_{2}$ & $0.5,0.5$ & $0 \cdot 69$ & $0 \cdot 64$ \\
\hline
\end{tabular}

* Corrected for $\mathbf{0 . 7}$ mole of deoxycytidine found as undegraded (CT)p. 
Table 5. Products obtained by treating a diphenylamine digest of DNA with osmium tetroxide followed by successive treatments with alkali, acidic diphenylamine and prostatic phosphatase

A diphenylamine digest of herring DNA was treated with $\mathrm{OsO}_{4}$ for $45 \mathrm{~min}$. in $0 \cdot 1 \mathrm{~N}-\mathrm{NH}_{3}$. The treatments with alkali and acidic diphenylamine are described in the legend to Fig. 7. The mixture was then treated with prostatic phosphomonoesterase before two-dimensional separation of the nucleotides on paper, according to either Burton \& Petersen (1960) or Petersen (1963). Individual values are shown.

\begin{tabular}{|c|c|c|}
\hline Product & $\begin{array}{l}\text { Amount (moles of } \\
\text { cytosine/ } 100 \text { moles } \\
\text { of DNA phosphate) }\end{array}$ & $\begin{array}{l}\text { Amount expected for } \\
\text { randomly arranged } \\
\text { polynucleotide }\end{array}$ \\
\hline C* $^{*}$ & $10 \cdot 3,10 \cdot 9,11 \cdot 1,11 \cdot 4$ & $13 \cdot 1$ \\
\hline $\mathrm{C}_{2} \mathrm{p}$ & $3 \cdot 3,3 \cdot 5,3 \cdot 6,3 \cdot 7$ & $\mathbf{5 \cdot 5}$ \\
\hline $\mathrm{C}_{3} \mathrm{p}_{2}$ & $1 \cdot 0,1 \cdot 1,1 \cdot 2,1 \cdot 5$ & $1 \cdot 73$ \\
\hline $\mathrm{C}_{4} \mathrm{p}_{3}$ & $0.4,0.4,0.5$ & 0.48 \\
\hline
\end{tabular}

* Includes 0.3-0.7 mole for deoxycytidine found as (CT)p resulting from incomplete oxidation by the $\mathrm{OsO}_{4}$.

also gave incomplete release of $P_{i}$, even when the initial oxidation stage had been taken to completion.

With a satisfactory sample of osmium tetroxide, the reaction is allowed to proceed for $6-7 \mathrm{~min}$. in $0.4 \mathrm{~N}$-ammonia. The reaction is then stopped by extracting excess of osmium tetroxide three times with 5 vol. of ice-cold ether. Potassium hydroxide $(2 \mathrm{~N})$ is added to the aqueous phase to give a final concentration of $0 \cdot 10 \mathrm{~N}$. After $2 \mathrm{hr}$. at $37^{\circ}$, the solution is desalted (see the Methods section) and the freeze-dried material is incubated for $15-20 \mathrm{hr}$. at $30^{\circ}$ in a suitable volume of $2 \%(\mathrm{w} / \mathrm{v})$ diphenylamine in $66 \%(v / v)$ formic acid. An equal volume of water is added, the diphenylamine and most of the formic acid is removed by ether extraction and, if necessary, the residual formic acid is removed by exhaustive extraction with ether or by evaporation in vacuo.

\section{DISCUSSION}

In this work, our aim has been to degrade selectively pyrimidine-containing oligodeoxynucleotides by oxidation at the ethylenic bond of the pyrimidine. Osmium tetroxide reacts much faster with thymine nucleotides than with cytosine nucleotides and its selectivity is retained on reaction with oligonucleotides. It is most likely that the pyrimidines condense with the tetroxide to form the 4,5-diolosmates and that the subsequent treatment with alkali opens the pyrimidine rings so that they form acid-labile ureidoglycosides. In this way it is possible to remove nucleotides almost quantitatively. Provided that correction is made for the unwanted degradation of cytosine compounds (5-10\%), the conditions described provide a potentially valuable method for investigating nucleotide sequences in DNA. The method may be particularly useful in examining sequences of pyrimidine deoxynucleotides such as those that have been isolated by Hall \& Sinsheimer (1963) from the DNA of bacteriophage $\phi \times 174$.

If the oligonucleotides have been treated with phosphomonoesterase before reaction with osmium tetroxide, any terminal cytosine sequences appear as nucleotides of the general formula $\mathrm{C}_{n} \mathrm{p}_{n}$, whereas interior cytosine nucleotides appear as $\mathrm{C}_{n} \mathrm{p}_{n+1}$ compounds. By suitable enzymic methods it should be possible to decide which of the $C_{n} p_{n}$ products have $3^{\prime}$-phosphate and which have $5^{\prime}$ phosphate end groups. With this information one could determine the sequence of any oligodeoxynucleotide that consisted of any number of cytosine nucleotide residues and up to two thymine nucleotide residues. The same procedure applied to a diphenylamine digest of DNA would give values for the frequencies of the various sequences $\mathrm{Pu}-\mathrm{C}_{n}-\mathrm{Pu}, \mathrm{T}-\mathrm{C}_{n}-\mathrm{Pu}$ and $\mathrm{Pu}-\mathrm{C}_{n}-\mathrm{T}$.

A disadvantage of the method is that the coloured colloidal reduced forms of osmium tetroxide are not easily separated from the oligonucleotide products of the degradation. Chromatography or electrophoresis on paper have been more useful for eliminating these colloidal materials than has column chromatography on DEAE-Sephadex or Dowex 1.

Although purine nucleotides are not attacked by osmium tetroxide, the conditions discovered for removing the oxidized thymine residues are sufficiently acid to remove the purines as well. The reactions cannot therefore be used to remove the thymine while leaving purine nucleotides intact. The reaction between oxidized pyrimidine oligonucleotides and the diphenylamine-formic acid reagent is somewhat slower than the reaction of the mononucleotides. This is not surprising in view of the fact that in the same reagent DNA reacts more slowly than the purine mononucleotides.

The series of reactions described cannot be used for base-sequence studies on RNA because uracil nucleotides are oxidized at a rate intermediate between those of thymine and cytosine nucleotides, and because the treatment with alkali would cause extensive degradation of RNA. In other experiments we have tried to replace the incubation with alkali by treatment with periodate, but the reaction is slow and incomplete.

Various structural modifications appeared to alter the rate of attack by osmium tetroxide in an independent manner. From Fig. 1 and other data, the relative rates of oxidation by osmium tetroxide in $0.4 \mathrm{~N}$-ammonia are, approximately: deoxycytidine, 1.0 ; cytidine, 1.8 ; deoxyuridine, $2 \cdot 8$; uridine, 4.5 ; 5-methyldeoxycytidine and 5-bromodeoxyuridine, 13; thymidine, 45. Thus the increase of 
reaction rate is about 15 times for the introduction of a 5-methyl group, 5 times on introducing a 5bromo substituent, $2 \cdot 5-2 \cdot 8$ times on replacing a 6-amino group by a 6-oxo group and 1.6-1.8 times on introducing a hydroxyl group at the 2 '-position of a deoxynucleoside.

A number of other selective reactions of the nucleotide bases in DNA have been described. Grossman \& Greenlees (1961) have shown that dihydropyrimidine nucleotides differ in their lability to acid. Deoxycytidine and its nucleotides are hydrolysed selectively by heating at $\mathrm{pH}$ 6-7 (Adamiec \& Shugar, 1959; Greer \& Zamenhof, 1962). Hydroxylamine (Verwoerd, Zillig \& Kohlhage, 1963) and hydrazine (Verwoerd \& Zillig, 1963) can react selectively with different pyrimidine nucleotides. Potassium permanganate oxidizes cytosine, thymine and guanine nucleotides, but adenine is resistant. In this way, the distribution of adenine may be examined in DNA or in polydeoxynucleotides (Jones, Ross, Takemura, Thompson \& Walker, 1964 ; Jones \& Walker, 1964). Simon \& Van Vunakis $(1962,1964)$ have shown that guanine is selectively photo-oxidized in the presence of methylene blue, but methods for the selective and quantitative removal of the oxidized guanine have not been described. In at least one instance (Jones et al. 1964 ) the reactions may occur readily with model compounds but only very slowly in polynucleotides.

We thank Mr N. F. Varney for his willing and skilled technical assistance. W. T. R. held a Medical Research Council Scholarship for Training in Research Methods. The work was aided by grants from the U.S. Public Health Service and the Rockefeller Foundation.

\section{REFERENCES}

Adamiec, A. \& Shugar, D. (1959). Naturwissenschaften, 46, 356.

Ayres, G. H. \& Wells, W. N. (1950). Analyt. Chem. 22, 317. Baudisch, O. \& Davidson, D. (1925). J. biol. Chem. 64, 233.
Berenblum, I. \& Chain, E. (1938). Biochem. J. 32, 295.

Burton, K. (1956). Biochem. J. 62, 315.

Burton, K. (1959). In Data for Biochemical Research, p. 74. Ed. by Dawson, R. M. C., Elliott, D. C., Elliott, W. H. \& Jones, K. M. Oxford: The Clarendon Press.

Burton, K. (1960). Biochem. J. 77, 547.

Burton, K. (1966). Biochem. J. 98, 68.

Burton, K. \& Petersen, G. B. (1960). Biochem. J. 75, 17.

Chen, P. S., Toribara, J. Y. \& Warner, H. (1956). Analyt. Chem. 28, 1756.

Cohn, W. E. (1956). Biochem. J. 64, 28 P.

Cohn, W. E. \& Doherty, D. G. (1956). J. Amer. chem. Soc. 78, 2863.

Coulombe, J. J. \& Favreau, L. (1963). Clin. Chem. 9, 102.

Emanuel, C. F. \& Chaikoff, I. L. (1953). J. biol. Chem. 203, 167.

Greer, S. \& Zamenhof, S. (1962). J. molec. Biol. 4, 123.

Grossman, L. \& Greenlees, J. (1961). Analyt. Biochem. 2, 189.

Hall, J. B. \& Sinsheimer, R. L. (1963). J. molec. Biol. 6, 115.

Hanes, C. S. \& Isherwood, F. A. (1949). Nature, Lond., 164, 1107.

Jones, A. S., Ross, G. W., Takemura, S., Thompson, T. W. \& Walker, R. T. (1964). J. chem. Soc. p. 373.

Jones, A. S. \& Walker, R. T. (1964). Nature, Lond., 202, 24.

Klobbie, E. A. (1898). Chem. Zbl. 11, II, 65.

Langseth, A. \& Qviller, B. (1934). Z. phys. Chem. B, 27, 79.

Nielsen, S. O. \& Lehninger, A. L. (1955). J. biol. Chem. 215, 555.

Pease, D. C. (1960). Histological Techniques for Electron Microscopy. New York: Academic Press Inc.

Petersen, G. B. (1963). Biochem. J. 87, 495.

Roberts, D. \& Friedkin, M. (1958). J. biol. Chem. 233, 483.

Simon, M. I. \& Van Vunakis, H. (1962). J. molec. Biol. 4, 488.

Simon, M. I. \& Van Vunakis, H. (1964). Arch. Biochem. Biophys. 105, 197.

Verwoerd, D. W. \& Zillig, W. (1963). Biochim. biophys. Acta, 68, 484.

Verwoerd, D. W., Zillig, W. \& Kohlhage, H. (1963). HoppeSeyl.Z. 332, 184.

Waravdekar, V.S. \& Saslaw, L. D. (1959). J.biol. Chem. 234, 1945. 